\title{
Variable-Number-of-Tandem-Repeats Analysis of Genetic Diversity in Pasteuria ramosa
}

\author{
L. Mouton · D. Ebert
}

Received: 10 September 2007/ Accepted: 30 November 2007/Published online: 24 January 2008

(C) Springer Science+Business Media, LLC 2008

\begin{abstract}
Variable-number-of-tandem-repeats (VNTR) markers are increasingly being used in population genetic studies of bacteria. They were recently developed for Pasteuria ramosa, an endobacterium that infects Daphnia species. In the present study, we genotyped P. ramosa in 18 infected hosts from the United Kingdom, Belgium, and two lakes in the United States using seven VNTR markers. Two Daphnia species were collected: D. magna and D. dentifera. Six loci showed length polymorphism, with as many as five alleles identified for a single locus. Similarity coefficient calculations showed that the extent of genetic variation between pairs of isolates within populations differed according to the population, but it was always less than the genetic distances among populations. Analysis of the genetic distances performed using principal component analysis revealed strong clustering by location of origin, but not by host Daphnia species. Our study demonstrated that the VNTR markers available for $P$. ramosa are informative in revealing genetic differences within and among populations and may therefore become an important tool for providing detailed analysis of population genetics and epidemiology.
\end{abstract}

\footnotetext{
L. Mouton $(\bowtie) \cdot$ D. Ebert

Evolutionsbiologie, Zoologisches Institut der Universitat Basel, Basel, Switzerland

e-mail: mouton@biomserv.univ-lyon1.fr

L. Mouton

Laboratoire de Biometrie et Biologie Evolutive, Universite de Lyon, Villeurbanne, France
}

\section{Introduction}

Bacteria of the genus Pasteuria, endospore-forming, Grampositive bacteria members of the Bacillus-Clostridium clade, are common parasites of nematodes and crustaceans. They can be highly virulent, such as $P$. ramosa, a pathogen of the freshwater crustacean Daphnia [12]. These bacteria most frequently infect Daphnia magna but are also found in D. pulex, D. longispina, and D. dentifera [10]. They have been recorded in Europe and North America, with a prevalence $\leq 80 \%$ [9]. P. ramosa are obligate extracellular parasites that grow in the body cavity of their hosts and produce several million endospores. Infected hosts suffer greatly decreased fecundity [11], which influences their population dynamics [6]. Transmission is strictly horizontal (waterborne) through spores released from the remains of dead hosts. These spores can remain dormant in pond sediment for decades [7].

Multiple-locus variable-number-of-tandem-repeats (VNTR) analysis is the method of choice for variability studies of many bacterial species, especially pathogens $[16,17,19$, 20 (review), 21, 26]. Indeed, VNTRs often provide a high level of discriminatory power for strain differentiation because of their high mutability [27]. Recently, VNTR markers were developed in P. ramosa [22]. In that study, genetic diversity was estimated based on sediment samples from different locations. A large degree of polymorphism was revealed within the material surveyed, indicating that these markers may constitute good tools for epidemiologic studies of natural populations. However, a better understanding of their effectiveness in determining the level of genetic diversity among $P$. ramosa isolates is a prerequisite for more effective survey.

In the present article, seven polymorphic VNTR markers were applied to study the genetic relationships among $P$. 
ramosa isolates found in field populations of Daphnia. Two species of Daphnia were collected, D. dentifera and D. magna, in three different geographic locations: the United Kingdom, Belgium, and the United States. Genetic diversity and relationships among populations were estimated using three similarity coefficient calculations: the Jaccard, Dice, and simple match coefficients [18]. Principal component analysis (PCA) showed that the VNTRs are able to discriminate between populations of $P$. ramosa. The Pasteuria-Daphnia system has been a model for many experimental studies of host-parasite interactions [10]. It is therefore of great interest to develop valuable molecular markers that provide information on the epidemiology, diversity, and evolution of $P$. ramosa in wild populations.

\section{Materials and Methods}

\section{Strains}

DNA of $P$. ramosa was extracted from 18 infected Daphnia collected in the field. Two Daphnia species were collected: Daphnia magna and D. dentifera. Infected D. dentifera came from two lakes in Michigan: Sherman Lake (Barry county; latitude $42.35^{\circ} \mathrm{N}, 85.39^{\circ} \mathrm{W}$ ) and Pine Lake (Kalamazoo county; latitude $42.57^{\circ} \mathrm{N}, 85.39^{\circ} \mathrm{W}$ ). Infected D. magna were collected in one pond in each in Belgium and the United Kingdom (Table 1).

\section{DNA Extraction and PCR Amplification}

Bacterial DNA was extracted using the EZNA Tissue DNA kit (Peqlab, Erlangen, Germany). Daphnia were individually crushed in microtubes containing $200 \mu \mathrm{l}$ TL buffer and $25 \mu \mathrm{l}$ proteinase $\mathrm{K}$ and maintained for 2 to 3 hours at $55^{\circ} \mathrm{C}$. Final elution volume was $100 \mu$ l. Polymerase chain reaction (PCR) amplification of seven VNTR loci [22] was carried out using seven primer sets (Table 2) in 25- $\mu$ l volumes containing $1 \times \mathrm{PCR}$ buffer [TrisCl, $\mathrm{KCl},\left(\mathrm{NH}_{4}\right)_{2} \mathrm{SO}_{4}$, $15 \mathrm{mM} \mathrm{MgCl}_{2}$; pH 8,7], $200 \mu \mathrm{M}$ deoxyribonucleoside triphosphate, $200 \mathrm{nM}$ primers, $0.5 \mathrm{U}$ HotStarTaq DNA polymerase (Qiagen $\mathrm{GmbH}$, Germany), and $2 \mu$ l template
DNA. Thermal cycling conditions were 15 minutes at $94^{\circ} \mathrm{C}$ followed by 40 cycles of 30 seconds at $94^{\circ} \mathrm{C}, 30$ seconds at $50^{\circ} \mathrm{C}$, and 1 minute at $72^{\circ} \mathrm{C}$. Final elongation was $10 \mathrm{~min}$ utes at $72^{\circ} \mathrm{C}$. Negative controls were done on DNA extracted from uninfected Daphnia magna to ensure that the VNTR amplicons were derived from the $P$. ramosa DNA.

\section{Automated Genotype Analysis}

The PCR products were electrophoretically analysed with an ABI 310 DNA sequencer. Genetic Analyser and Genemapper software packages (Applied Biosystem, Warrington, UK) were used to analyse sample sizes as described in Mouton et al. [22].

\section{Data Analysis}

Genetic similarities and relationships among the samples were estimated by multivariate analysis based on the presence or absence of each detected allele at each locus. A similarity matrix was calculated from these data based on the proportion of shared alleles across all loci. The genetic dissimilarity between pairs of individuals was estimated for all possible pair-wise comparisons within and between populations using three different coefficients: the Jaccard, Dice, [23], and simple match coefficients [25]. We denoted as "A" the number of alleles common to both individuals and populations, as " $\mathrm{B}$ " the number of alleles unique to the first individual and population $\left(i_{1}\right)$, as " $C$ " the number of alleles unique to the second individual and population $\left(i_{2}\right)$, and as " $n$ " the total number of alleles that appeared in at least one of the two individuals and populations $\left(i_{1}\right.$ and $\left.i_{2}\right)$. Coefficients of dissimilarity between individuals and populations $i_{1}$ and $i_{2}$ could then be calculated as follows [18 (review)]:

Jaccard's coefficient: $j(i 1, i 2)=(\mathrm{B}+\mathrm{C}) /(\mathrm{A}+\mathrm{B}+\mathrm{C})$

Dice's coefficient: $d(i 1, i 2)=(\mathrm{B}+\mathrm{C}) /(2 \mathrm{~A}+\mathrm{B}+\mathrm{C})$

Simple match coefficient $m(i 1, i 2)=(\mathrm{B}+\mathrm{C}) / n$.

In addition, the VNTR marker data for the 18 daphnia samples were scored for the two first principal components,

Table 1 P. ramosa samples

\begin{tabular}{lllr}
\hline Population & Host species & Geographic region & $\begin{array}{c}\text { Sampling } \\
\text { Year } \\
\text { hosts tested }\end{array}$ \\
\hline BE OM1 & Daphnia magna & Heverlee, Belgium, Pond OM1 & 2006 \\
UK K1 & Daphnia magna & Kames, UK, Pond 1 & 2006 \\
AM Sh & Daphnia dentifera & USA, Michigan, Sherman Lake & 2005 \\
AM Pi & Daphnia dentifera & USA, Michigan, Pine Lake & 5 \\
\hline
\end{tabular}


Table 2 Repetitive DNA PCR primer sequences and attributes

\begin{tabular}{|c|c|c|c|c|c|c|}
\hline $\begin{array}{l}\text { Primer } \\
\text { names }\end{array}$ & Primer sequences & Locus name & Repeat motif & Size range $(\mathrm{nt})^{\mathrm{a}}$ & $\begin{array}{l}\text { Smallest- } \\
\text { largest } \\
\text { no. of } \\
\text { repetitions }\end{array}$ & $\begin{array}{l}\text { No. of } \\
\text { alleles }\end{array}$ \\
\hline $\begin{array}{l}\text { Pr1 fwd } \\
\text { Pr1 rev }\end{array}$ & $\begin{array}{l}\text { ACCTAAAGAACAGGAATATCTGGA } \\
\text { GCATGGAATGATTTTTGCTG }\end{array}$ & Pr SSR1 & AAACTAACA & $195-276$ & $3-11$ & 4 \\
\hline $\begin{array}{l}\text { Pr2 fwd } \\
\text { Pr2 rev }\end{array}$ & $\begin{array}{l}\text { CTGCTGGATGGATGGACTACGTGA } \\
\text { ACCGGTCCCGTAGGTATAGG }\end{array}$ & $\begin{array}{l}\text { Pr SSR2.1 } \\
\text { Pr SSR2.2 }\end{array}$ & $\begin{array}{l}\text { CCTGGTAAA } \\
\text { CATCCTGGTGGTCCTTGG }\end{array}$ & $259-286$ & $\begin{array}{l}3-4 \\
2-3\end{array}$ & 2 \\
\hline $\begin{array}{l}\text { Pr3 fwd } \\
\text { Pr3 rev }\end{array}$ & $\begin{array}{l}\text { GGACCAATCGAACCAGGTAT } \\
\text { AACGGTTTCTTCGCTTGTTG }\end{array}$ & Pr SSR3 & TATCTCСТTTAGGACCAG & $365-392$ & $6-9$ & 3 \\
\hline $\begin{array}{l}\text { Pr4 fwd } \\
\text { Pr4 rev }\end{array}$ & $\begin{array}{l}\text { GGTAACCCTGGATGTCCTGA } \\
\text { ATCCCGTTACAAATGGGACA }\end{array}$ & Pr SSR4 & TT(A/G)CTTTA* & $321-369$ & $9-15$ & 3 \\
\hline $\begin{array}{l}\text { Pr7 fwd } \\
\text { Pr7 rev }\end{array}$ & $\begin{array}{l}\text { AACGTACTGACAAACCAAACCA } \\
\text { AATTTTTCTTAGATTGCTAGGTTGA }\end{array}$ & Pr SSR7 & AACAACC(T/C)C & $109-172$ & $4-11$ & 5 \\
\hline $\begin{array}{l}\text { Pr8 fwd } \\
\text { Pr8 rev }\end{array}$ & $\begin{array}{l}\text { GCATCAAATACAAAAACAAATGAAG } \\
\text { TGTTTCTCTCGCGTTTCCTT }\end{array}$ & Pr SSR8 & AGAATATGAAGAAGATGC & $404-440$ & $5-7$ & 3 \\
\hline $\begin{array}{l}\text { Pr9 fwd } \\
\text { Pr9 rev }\end{array}$ & $\begin{array}{l}\text { ATACGACGAACGGAACAAGA } \\
\text { AACCAAAGAATTAACGCCATT }\end{array}$ & Pr SSR9 & AGCAACAAC & 178 & 5 & 1 \\
\hline
\end{tabular}

VNTRs located within putative coding region are indicated in bold. No significant similarities were found when compared the corresponding amino acid sequences with protein sequence databases at the NCBI database [22]

* Imperfect repetitions. The two nucleotides in the parenthesis can be found

a Size range of amplicons

b The smallest and the largest number of repetitions found in the samples

c Number of alleles in the samples

and PCA was plotted using Multi-Variate Statistical Package Version 3.1 (Kovach Computing Services).

\section{Results}

\section{VNTR Amplification}

Table 3 lists the alleles present at the seven primer sets for each of the 18 samples screened. A summary of the alleles' size-range and the corresponding numbers of repeats are listed in Table 2. For all these primers, PCR allowed amplification of the field samples irrespective of the host, $D$. magna or D. dentifera, indicating that the VNTR regions selected for typing were conserved among the $P$. ramosa that infected different Daphnia species. However, we failed to amplify some samples from the United States with the primer set Pr3, which may be explained by mutations in the binding regions of the primers, resulting in the loss of the PCR product (null alleles). Except for Pr SSR9, all markers proved to be effective in discriminating the isolates analysed, especially Pr SSR1, for which each population had a specific allele. However, the extent of polymorphism was variable, with as many as 5 alleles/ locus observed in Pr SSR7. For this locus, some individuals harbour two different alleles, which may reflect the simultaneous presence of $>1 P$. ramosa clones within a host individual. However, we cannot fully exclude the existence of a technical artefact caused by PCR stutter or the instability of this marker because repetitive DNA sequences has been described in other repetitive DNA in eukaryotes and prokaryotes [1, 2]. Further investigations are necessary to test these hypotheses.

Genetic Similarities and Relationships Among Isolates

Genetic distances of $P$. ramosa between and within the four infected host populations sampled were estimated using dissimilarity coefficients based on the proportion of shared alleles of $P$. ramosa among Daphnia individuals across the seven VNTR loci. According to Kosman and Leonard [18], Dice's coefficient is the more appropriate measure for studying similarity between haploid individuals with VNTR markers. However, two other coefficients of dissimilarity commonly used for comparison between individuals, the Jaccard and simple match coefficients, were also calculated to test the robustness of the comparisons (Table 4). These three indices gave similar results (Spearman order rank correlation coefficient, rho $=1$ ), 
Table 3 Amplicons size (nt) of the 18 infected host individuals from four populations

\begin{tabular}{|c|c|c|c|c|c|c|c|c|}
\hline \multirow[t]{2}{*}{ Population $^{\mathrm{a}}$} & \multirow{2}{*}{$\begin{array}{l}\text { Individual } \\
\text { number }\end{array}$} & \multicolumn{7}{|c|}{ Primer } \\
\hline & & Pr1 & $\operatorname{Pr} 2$ & $\operatorname{Pr} 3$ & Pr4 & Pr7 & Pr8 & Pr9 \\
\hline BE OM1 & 1 & 276 & 286 & 383 & 321 & 163 & 404 & 178 \\
\hline BE OM1 & 2 & 276 & 286 & 383 & 345 & 163 & 404 & 178 \\
\hline BE OM1 & 3 & 276 & 286 & 383 & 345 & 163 & 404 & 178 \\
\hline UK K1 & 1 & 240 & 259 & 365 & 369 & 163 & 404 & 178 \\
\hline UK K1 & 3 & 240 & 259 & 365 & 369 & $\begin{array}{l}163 \\
172\end{array}$ & 404 & 178 \\
\hline UK K1 & 4 & 240 & 259 & 365 & 369 & 163 & 404 & 178 \\
\hline UK K1 & 5 & 240 & 259 & 365 & 369 & 163 & 404 & 178 \\
\hline UK K1 & 7 & 240 & 259 & 365 & 369 & 163 & 404 & 178 \\
\hline AM Sh & 1 & 249 & 259 & 365 & 321 & $\begin{array}{l}145 \\
154\end{array}$ & 422 & 178 \\
\hline AM Sh & 2 & 249 & 259 & 365 & 321 & $\begin{array}{l}145 \\
154\end{array}$ & 422 & 178 \\
\hline AM Sh & 3 & 249 & 259 & 365 & 321 & $\begin{array}{l}145 \\
154\end{array}$ & 422 & 178 \\
\hline AM Sh & 4 & 249 & 259 & 365 & 321 & 145 & 422 & 178 \\
\hline AM Sh & 5 & 249 & 259 & 365 & 321 & 154 & 422 & 178 \\
\hline AM Pi & 1 & 195 & 286 & $\mathrm{x}$ & 345 & 163 & 440 & 178 \\
\hline AM Pi & 2 & 195 & 259 & $\mathrm{x}$ & 345 & 163 & 440 & 178 \\
\hline $\mathrm{AM} P \mathrm{Pi}$ & 3 & 195 & 259 & 365 & 345 & 163 & 440 & 178 \\
\hline AM Pi & 4 & 195 & 286 & 392 & 345 & $\begin{array}{l}109 \\
163\end{array}$ & 440 & 178 \\
\hline $\mathrm{AM} P \mathrm{Pi}$ & 5 & 195 & 259 & 365 & 345 & 109 & 440 & 178 \\
\hline
\end{tabular}

$\mathrm{x}$ : Amplification failed

${ }^{\text {a }}$ for abbreviations see Table 1

indicating the reliability of the conclusions. The mean distances between isolate pairs within the same population were smaller than the distances between isolates from different populations. The extent of genetic diversity varied among populations (Kruskal-Wallis, $\mathrm{H}=16.1$, $P=0.0018$ for Dice's coefficient), with the United

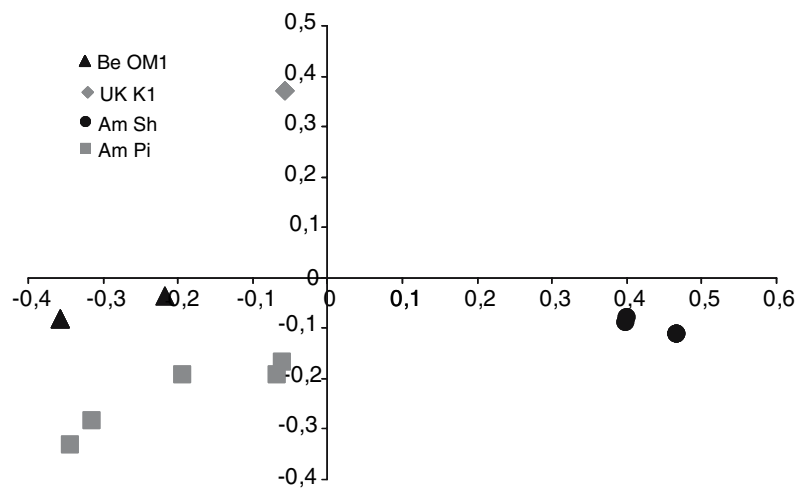

Fig. 1 Principal Component Analysis (PCA) plots from SSR data The PCA plots are components 1 (horizontal axis) vs 2 (vertical axis). Samples with identical VNTRs pattern overlap. Therefore less points than sampled individuals are visible

Kingdom population having the lowest and the American population from Pine Lake the highest level of dissimilarity, i.e., individual infections were the least similar within the AM Pi population.

PCA performed on the 18 samples reflected a strong clustering by location of origin but did not show clustering by host Daphnia species (Fig. 1). Data are shown for the first two components axes, representing $40.2 \%$ and $27.2 \%$ of the total variation, respectively. Belgium and United Kingdom bacteria were collected from the same Daphnia species, D. magna, whereas bacteria from the two American populations were isolated from $D$. dentifera. Data also showed that the populations collected in two different lakes in United States were distinct.

\section{Discussion}

Recently, the first molecular markers discriminating $P$. ramosa isolates were described [22]. To date, the only way to classify Pasteuria strains was through their infection
Table 4 Genetic dissimilarities between $P$. ramosa samples

The genetic distances within and between $P$. ramosa populations were estimated on the basis of the Jaccard, Dice and simple match dissimilarity coefficients as described in the material and methods section. For within comparisons, number of pairwise comparisons (n), means and standard errors $( \pm)$ are indicated

\begin{tabular}{llrlll}
\hline Comparison & & $\mathrm{n}$ & $\begin{array}{l}\text { Jaccard 's } \\
\text { coefficient }\end{array}$ & $\begin{array}{l}\text { Dice's } \\
\text { coefficient }\end{array}$ & $\begin{array}{l}\text { Simple match } \\
\text { coefficient }\end{array}$ \\
\hline Within populations & BE OM1 & 3 & $0.17 \pm 0.08$ & $0.10 \pm 0.05$ & $0.17 \pm 0.08$ \\
& UK K1 & 10 & $0.05 \pm 0.02$ & $0.03 \pm 0.01$ & $0.05 \pm 0.02$ \\
& AM Sh & 10 & $0.10 \pm 0.03$ & $0.05 \pm 0.01$ & $0.10 \pm 0.03$ \\
& AM Pi & 10 & $0.31 \pm 0.05$ & $0.20 \pm 0.04$ & $0.31 \pm 0.05$ \\
Between populations & BE OM1 / UK K1 & 0.77 & 0.63 & 0.77 \\
& BE OM1 / AM Sh & 0.86 & 0.75 & 0.86 \\
& BE OM1 / AM Pi & 0.71 & 0.56 & 0.71 \\
& UK K1 / AM Sh & 0.77 & 0.63 & 0.77 \\
& UK K1 / AM Pi & 0.71 & 0.56 & 0.71 \\
& AM Sh / AM Pi & 0.80 & 0.67 & 0.80 \\
\hline
\end{tabular}


profile $[3,5,24]$. In this article, we used available VNTR markers to evaluate genetic diversity and relationships of $P$. ramosa in infected Daphnia individuals and populations from the United Kingdom, Belgium, and the United States. This study of $P$. ramosa epidemiology showed that these markers are informative in revealing genetic differences among populations.

The genetic distance between pairs of $P$. ramosa isolates from individual Daphnia at the four geographic locations was estimated on the basis of three similarity coefficients (the Jaccard, Dice, and simple match coefficients). The values obtained with these coefficients showed that the extent of genetic diversity among populations varies, but that in all cases, genetic similarity is higher within than between populations. Allozyme analysis of D. magna populations revealed strong genetic divergences in relation to geographic distance [13]. Therefore, these results could reflect a specialization of parasites to the local host genotypes, which is consistent with previous data showing specific Daphnia clone-P. ramosa isolate interactions [3, 8]. A geographic pattern of population differentiation was revealed by PCA. However, the influence of geographic distance between populations is difficult to test here because the $P$. ramosa isolates came from two host species: $D$. magna and $D$. dentifera. Surprisingly, the $P$. ramosa infecting these two different Daphnia species showed no split, suggesting that the Daphnia species does not affect the genetic diversity of $P$. ramosa; however, more investigations are needed to clarify this question. Although the four populations showed clear genetic differences, there was also some within-population variation among bacteria from different host individuals. Large within-population variation has been reported before for $P$. ramosa, but it was based on phenotypic infection profiles [3, 13] and thus attributed to local coevolution between hosts and parasites.

We demonstrated that VNTRs are a useful resource for studying genetic diversity in $P$. ramosa. Therefore, this method can be used in epidemiologic and phylogenetic studies. It has been suggested that parasite genetic variability is a driving force of host and parasite evolution and host-parasite arms races [14, 15]. Moreover, the effect of parasite infection on host reproduction and survival, combined with genetic variation in the host-parasite association, might be responsible for coevolution based on frequency-dependent selection [3]. Investigating the genetic variability of hosts (microsatellite markers have been developed in D. pulex [4] and D. magna (I. Colson, in preparation) and their parasites is a way to test the hypothesis of coevolution between P. ramosa and their hosts.

Acknowledgments We thank I. Colson and L. Du Pasquier for useful discussion and comments, B. Aeschbach for technical help, and T. Little, E. Decaestecker, and S. Hall for providing samples. S.
Zweizig and I. Colson improved the English language of the manuscript. This work was supported by grants from the Swiss Nationalfonds and the Freiwillige Akademische Geselschaft, Basel, Switzerland.

\section{References}

1. Bois PR (2003) Hypermutable minisatellites, a human affair? Genomics 81:349-355

2. Bzymek M, Lovett ST (2001) Instability of repetitive DNA sequences: The role of replication in multiple mechanisms. Proc Natl Acad Sci U S A 98:8319-8325

3. Carius HJ, Little T, Ebert D (2001) Genetic variation in a hostparasite association: Potential for coevolution and frequencydependent selection. Evolution 55:1146-1152

4. Colbourne JK, Robison B, Bogart K, Lynch M (2004) Five hundred and twenty-eight microsatellite markers for ecological genomic investigations using Daphnia. Mol Ecol Notes 3:485490

5. Davies KG, Redden M (1997) Diversity and partial characterization of putative virulence determinants in Pasteuria penetrans, the hyperparasitic bacterium of root-knot nematodes (Meloidogyne spp.). J Appl Microbiol 83:227-235

6. Decaestecker E, Declerck S, De Meester L, Ebert D (2005) Ecological implications of parasites in natural Daphnia populations. Oecologia 144:382-390

7. Decaestecker E, Lefever C, De Meester L, Ebert D (2004) Haunted by the past: Evidence for dormant stage banks of microparasites and epibionts of Daphnia. Limnol Oceanogr 49:1355-1364

8. Decaestecker E, Vergote A, Ebert D, De Meester L (2003) Evidence for strong host-clone-parasite interactions in the Daphnia microparasite system. Evolution 57:784-792

9. Duncan AB, Mitchell SE, Little TJ (2006) Parasite-mediated selection and the role of sex and diapause in Daphnia. J Evol Biol 19:1183-1189

10. Ebert D (2005) Ecology, epidemiology, and evolution of parasitism in Daphnia. Bethesda, MD: National Library of Medicine, National Center for Biotechnology Information. Available from: http://www.ncbi.nlm.nih.gov/entrez/query.fcgi?db=books. Accessed:

11. Ebert D, Carius H-J, Little TJ, Decaestecker E (2004) The evolution of virulence when parasites cause host castration and gigantism. Am Nat 164(Suppl.):S19-S32

12. Ebert D, Rainey P, Embley TM, Scholz D (1996) Development, life cycle, ultrastructure and phylogenetic position of Pasteuria ramosa Metchnikoff 1888: Rediscovery of an obligate endoparasite of Daphnia magna Straus. Phil Trans Royal Soc London B 351:1689-1701

13. Ebert D, Zshokke-Rohringer CD, Carius HJ (1998) Within- and between-population variation for resistance of Daphnia magna to the bacterial endoparasites Pasteuria ramosa. Proc R Soc Lond B Biol Sci 265:2127-2134

14. Haldane JBS (1949) Disease and evolution. Ric Sci 19:2-11

15. Hamilton WD (1980) Sex versus non-sex versus parasite. Oikos 35:282-290

16. Keim P, Price LB, Klevytska AM, Smith KL, Schupp JM, Okinaka $R$ et al (2000) Multiple-locus variable-number tandem repeat analysis reveals genetic relationships within Bacillus anthracis. J Bacteriol 182:2928-2936

17. Klevytska AM, Brice LB, Schupp JM, Worsham PL, Wong J, Keim P (2001) Identification and characterization of variablenumber of tandem repeats in the Yersinia pestis genome. J Clin Microbiol 39:3179-3185 
18. Kosman E, Leonard KJ (2005) Similarity coefficients for molecular markers in studies of genetic relationships between individuals for haploid, diploid, and polyploid species. Mol Ecol $14: 415-424$

19. Liao J-C, Li C-C, Chiou C-S (2006) Use of multilocus variablenumber tandem repeat analysis method for molecular subtyping and phylogenetic analysis Neisseria meningitides isolates. BMC Microbiol 6:44

20. Lindstedt B-A (2005) Multiple-locus variable number tandem repeats analysis for genetic fingerprinting of pathogenic bacteria. Electrophoresis 26:2567-2582

21. Maiden MC, Bygraves JA, Feil E, Morelli G, Russel JE, Urwin $\mathrm{R}$ et al (1998) Multilocus sequence typing: A portable approach to the identification of clones within populations of pathogenic microorganisms. Proc Natl Acad Sci U S A 95:3140-3145

22. Mouton L, Nong G, Preston J, Ebert D (2007) Identification and characterization of variable number tandem repeats in an obligate endoparasite of Daphnia species. Appl Environ Microbiol 73:3715-3718

23. Nei M, Li WH (1979) Mathematical model for studying genetic variation in terms of restriction endonucleasis. Proc Natl Acad Sci U S A 76:5269-5273

24. Preston JF, Maruniak JE, Nong G, Brito JA, Schmidt LM, GiblinDavis RM (2003) Pasteuria spp.: Systematics and phylogeny of these bacterial parasites of phytopathogenic nematodes. J Nematol 35:198-207

25. Sneath PA, Sokal RR (1973) Numerical taxonomy. Freeman, San Francisco, CA

26. Top J, Schouh LM, Bonten MJ, Willems RJ (2004) Multilocus variable number of tandem repeats analysis, a novel typing scheme to study the genetic relatedness and epidemiology of Enterococcus faecium isolates. J Clin Microbiol 42:4503-4511

27. van Belkum A, Scherer S, van Alphen L, Verbrugh H (1998) Short-sequence DNA repeats in prokaryotic genomes. Microbiol Mol Biol Rev 62:275-293 